\title{
Endoscopic treatment of inverted papilloma attached in the frontal sinus/recess*
}

\author{
Gwijde F. J. P. M. Adriaensen, Maarten W. van der Hout, Susanne M. Reinartz, Rhinology 53:317-324, 2015 \\ Christos Georgalas, Wytske J. Fokkens \\ DOl:10.4193/Rhino14.177 \\ Department of Otorhinolaryngology, Academic Medical Centre (AMC), Amsterdam, the Netherlands \\ *Received for publication: \\ July 22, 2014 \\ Accepted: May 25, 2015
}

\begin{abstract}
Background: Inverted papilloma (IP) is a benign sinonasal tumour for which endoscopic surgery, with complete removal of the underlying and surrounding mucoperiosteum at the attachment site followed by drilling and/or coagulation of this area, is the treatment of choice. This can be challenging in the frontal sinus.
\end{abstract}

Objectives: To report on the outcome of treatment for IPs involving the frontal sinus. To propose the possible use of topical 5-fluorouracil 5\% (5-FU) in the postoperative management of challenging IPs.

Methods: This is a retrospective cohort evaluation of patients with IPs attached in the frontal sinus or in the frontal recess and growing into the frontal sinus. Data on primary or revision surgery, uni- or bilaterality, attachment site, surgical procedure, 5-FU usage, recurrence and follow-up are provided. The end points are disease-free follow-up in months and recurrence.

Results: Twenty cases, including fifteen revision cases, were retrieved over a period of ten years. All cases were treated endoscopically. Two cases recurred (10\%) and the intervention was repeated. In eight cases, 5-FU was applied at the end of surgery. None of these cases recurred. The mean follow-up after the last intervention was 42 months (standard deviation (SD) 22.1).

Conclusion: IP involving the frontal sinus is a surgical challenge that can be successfully addressed endoscopically. The topical application of 5-FU could have a place in postoperative treatment when it is difficult to be absolutely sure that all diseased mucoperichondrium or mucoperiosteum at the attachment site(s) has been completely removed.

Key words: inverted papilloma, frontal sinus, endoscopic sinus surgery, 5-fluorouracil

\section{Introduction}

The inverted papilloma (IP) is a relatively uncommon benign epithelial tumour of the nasal cavity. With an incidence ranging from 0.6 to 1.5 cases per 100,000 inhabitants per year, it accounts for 0.5 to 4 percent of surgically removed nasal tumours (1). IP originates from sinonasal mucosa and differentiation from other types of sinonasal (Schneiderian) papilloma like exophytic or oncocytic papilloma is based on the growth pattern, which involves a tendency to invert into the underlying connective tissue stroma. There is an association with synchronous as well as metachronous malignancy, making surgical removal the treatment of choice. The human papillomavirus (HPV) has been im- plicated in the pathogenesis of IP and possibly the development of associated malignancy ${ }^{(2)}$. Unfortunately, IP has a tendency to recur. Recurrence is associated with the incomplete removal of the tumour and might often actually be residual disease at the site of origin ${ }^{(3)}$. Removing a margin of neighbouring mucosa with a normal appearance together with the periosteum and/ or perichondrium, followed by drilling and coagulation of the attachment site(s), may reduce the rate of recurrence ${ }^{(1,4,5)}$. Most recurrent disease appears to occur in the first year of follow-up ${ }^{(6)}$. Once the IP recurs, the risk of subsequent recurrence rises to $18-58 \%{ }^{(7-9)}$.

Locating the attachment site is essential in planning surgical 
resection and achieving complete extirpation. IPs are most frequently attached in the ethmoid region (48\%), followed by the maxillary sinus (28\%), the sphenoid sinus $(7.5 \%)$, the inferior turbinate (2.5\%), septum (2.5\%) and frontal sinus $(2.5 \%){ }^{(10)}$. Reports indicate that $\mathrm{CT}$ imaging can show some focal hyperostosis or sclerosis of bone that suggest the origin of the IP ${ }^{(11,12)}$. However, an article by Badaai et al. used an independent radiologist to predict the site of attachment using the degree of osteitis. They found a predictive value for the radiological localisation of IP origin of $41 \%{ }^{(13)}$. An MRI scan typically shows a striated or convoluted cerebriform pattern in the IP on T2 or contrast-enhanced T1 setting, the direction of which seems to point towards the origin ${ }^{(14)}$. Furthermore, MRI imaging is very helpful in delineating the extent of the papilloma from an obstructed sinus filled with mucus ${ }^{(15-17)}$. Clinical evaluation, imaging and information about the usual attachment sites should be combined to localise the origin and extent of IPS.

Over the years, the preferred method for treating IPs has shifted from external procedures towards endoscopic resection ${ }^{(1,18)}$. However, the narrow anatomy in the frontal recess and lateral pneumatisation over the orbit mean that the frontal sinus continues to be an area that is endoscopically challenging. Since frontal sinus IP is uncommon, there are only a few case series that provide evidence for the successful endoscopic management of frontal IP ${ }^{(19,20)}$. Walgama published a systematic review of the surgical management of frontal sinus IP in 2012, looking at 49 cases from 11 studies conducted between 1995 and 2010. Statistical analysis of the data failed to identify the best surgical approach $^{(21)}$.

5-fluorouracil (5-FU) is a structural thymidine analogue that interferes with DNA synthesis and is used to treat epithelial malignancies because of its action on proliferating cells. Topical 5-FU is used for a range of purposes, including the treatment of actinic keratosis, superficial basal cell carcinoma of the skin ${ }^{(22)}$ and surface squamous neoplasia of the eye ${ }^{(22)}$. In the nose and sinus, 5-FU has been used as an adjunct therapy after surgical debulking for the treatment of adenocarcinoma of the ethmoidal sinus complex ${ }^{(24)}$. The prolonged and repeated topical administration of 5-FU improves long-term disease-free survival. The data reported by the Rotterdam group ${ }^{(24)}$ has recently been confirmed by a case-controlled study of 20 years of experience with adenocarcinoma in which the authors suggest using topical 5-FU to treat other locally aggressive sinonasal malignancies (25).

We present a large single-centre series of endoscopically managed inverted papillomas with frontal sinus involvement. A clear distinction is made between attachment inside and outside the frontal sinus. Surgical and follow-up data are provided. In addition, the use of topical 5-FU 5\% is described in, and proposed for, the postoperative management of challenging frontal IP surgery.
Table 1. Patient characteristics and previous surgical procedures.

\begin{tabular}{|c|c|c|c|}
\hline Case & $\begin{array}{c}\text { Age } \\
\text { (years) } \\
\text { /sex }\end{array}$ & $\begin{array}{l}\text { Revi- } \\
\text { sion }\end{array}$ & Previous procedures \\
\hline 1. & $11 / F$ & Yes & 1 partial/anterior ethmoidectomy \\
\hline 2. & $54 / \mathrm{M}$ & Yes & 1 partial/anterior ethmoidectomy \\
\hline 3. & $65 / M$ & No & - \\
\hline 4. & $64 / F$ & Yes & 1 partial/anterior ethmoidectomy \\
\hline 5. & $64 / M$ & No & - \\
\hline 6. & $43 / \mathrm{M}$ & Yes & 1 partial/anterior ethmoidectomy \\
\hline 7. & 82/M & No & - \\
\hline 8. & $37 / M$ & Yes & 1 anterior and posterior ethmoidectomy \\
\hline 9. & $47 / \mathrm{M}$ & Yes & 1 anterior and posterior ethmoidectomy \\
\hline 10. & $60 / \mathrm{M}$ & Yes & 1 lateral rhinotomy \\
\hline 11. & $83 / \mathrm{M}$ & Yes & 1 lateral rhinotomy, 1 polypectomy \\
\hline 12. & $49 / \mathrm{M}$ & Yes & 1 anterior and posterior ethmoidectomy \\
\hline 13. & $43 / \mathrm{M}$ & Yes & $\begin{array}{c}1 \text { anterior and posterior ethmoidectomy, } \\
1 \text { Draf } 2 a\end{array}$ \\
\hline 14. & $56 / \mathrm{M}$ & Yes & $\begin{array}{c}1 \text { anterior and posterior ethmoidectomy, } \\
2 \text { Draf } 3\end{array}$ \\
\hline 15. & $46 / \mathrm{M}$ & Yes & 1 polypectomy \\
\hline 16. & $45 / F$ & No & - \\
\hline 17. & $63 / \mathrm{M}$ & Yes & 1 partial/anterior ethmoidectomy \\
\hline 18. & $50 / \mathrm{M}$ & Yes & 1 polypectomy, 2 Denker rhinotomy \\
\hline 19. & $52 / \mathrm{M}$ & No & - \\
\hline 20. & $59 / \mathrm{M}$ & Yes & 1 anterior and posterior ethmoidectomy \\
\hline
\end{tabular}

\section{Materials and methods}

Study design

A retrospective chart review was performed in a single academic tertiary referral centre to identify inverted papilloma cases with involvement of the frontal sinus over the previous ten years (2003-2013).

\section{Patient population}

Information was collected about patient characteristics: age at last intervention, sex, primary or revision operation, the nasal side of involvement (right, left or bilateral), actual frontal recess or frontal sinus attachment, type of procedure performed, the use of adjunct 5-FU, possible adverse drug reactions to 5-FU, 
recurrence and follow-up in months. Table 1 lists the numbers and types of previous surgical procedures outside our centre.

\section{Diagnosis and definitions}

Diagnosis was confirmed on the basis of the pathology reports on the initial biopsy. In addition, reports on the entire specimen retrieved during endoscopic sinus surgery were reviewed to assess dysplasia or malignancy. Frozen sections were not taken during surgery but, when deemed necessary, topographic biopsies of wound edges were sent with the entire specimen.

Frontal sinus involvement was subdivided into two categories on the basis of attachment sites: IPs attached in the frontal recess and extending into the frontal sinus; and attachment of the IP inside the frontal sinus. Attachment sites and extension were mainly established on the basis of the OR report, and confirmed using data from imaging studies, CT and MRI, and topographic biopsies taken during surgery.

A revision case is defined as any case in which there has been previous surgery for IP not conducted by our centre.

A recurrence is defined as any case with a recurrence of disease after surgery in our centre. This can be residual disease after previous incomplete resection or a true recurrence after total removal.

\section{Radiology}

CT scans were made using a low-dose sinus protocol ( $25 \mathrm{mAs})$ with $1.5 \mathrm{~mm}$ slices and reconstructions in 3 planes. On MRI, T2weighted images and, if available, contrast-enhanced T1-weighted images were used to assess the possible attachment site and to delineate IP from surrounding mucosa or mucus to assess extension (Avanto 76 x 18, 1.5T, Siemens, Erlangen, Germany).

\section{Procedures}

We report the numbers and types of all surgical procedures in our centre. Endoscopic interventions were performed primarily using a 30 degree, $4 \mathrm{~mm}$ endoscope (Storz, Hopkins ${ }^{\circledast}$ II) with a clear vision system (Storz ${ }^{\oplus}$ ) and an HD camera (Storz, H3-Z ${ }^{\oplus}$ ). Peroperative radiological image navigation was available in all cases.

All surgery was performed under general anaesthesia. On each nasal side, three cotton tips soaked in crystalline cocaine (100 $\mathrm{mg}$ ) dissolved in adrenaline $(1 \mathrm{mg} / \mathrm{ml})$ were used for local anaesthesia and vasoconstriction.

When the size and extent of the tumour permitted, en-bloc resections were performed. A cuff $(0.5-1 \mathrm{~cm})$ of mucosa with a normal appearance surrounding the attachment was marked using diathermy and excised together with the lesion. Next, the bone underlying the attachment was drilled using a diamond drill. In areas where the bone was too thin, gentle coagulation was used.

In revision cases with unclear attachment site (multiple or

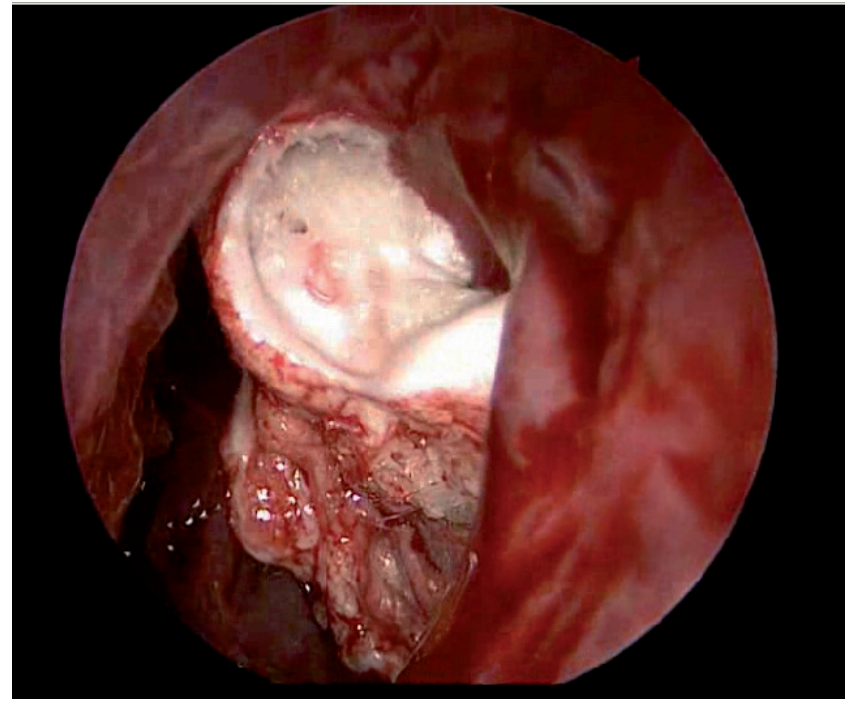

Figure 1. Jelonet gauze covered with 5-fluorouracil 5\% cream being placed at end of Draf 3 procedure.

single) or in which tumour location or size prevented en-bloc resection, the IP was initially resected piecemeal or debulked using Blakesley forceps and/or a microdebrider. Once the origin was located, resection followed as described above. All operative specimens, including microdebrider contents, were sent for pathological investigation.

The surgical cavity was routinely packed with jelonet gauze or merocel impregnated with either antibiotic hydrocortisone cream or topical 5-FU cream to ensure good contact with resected surfaces for 7-10 days. Oral antibiotics were prescribed until the packing was removed in the outpatient clinic.

\section{Topical 5-fluorouracil 5\% (5-FU)}

5-FU was used in cases where it was difficult to be absolutely sure that all diseased mucoperichondrium or mucoperiosteum had been completely removed, examples being hard-to-reach anatomical locations and/or when it was impossible to drill and coagulate without potentially causing serious morbidity, for example when there was attachment to the cribriform plate or distant lateral attachment in the frontal sinus on the orbital roof. At the end of surgery a jelonet gauze or merocel covered with 5-FU 5\% cream (Efudix ${ }^{\circledast}$ ) was placed in the whole surgical cavity (Figure 1) and left in situ for 7-10 days before being removed with repeated careful cleaning of the surgical cavity in the outpatient setting.

\section{Outcome measurements}

We evaluated recurrence rate and time to recurrence, procedures performed and disease-free follow-up in months for the group as a whole and for the cases that received 5-FU in their postoperative treatment. The 5-FU group was closely monitored 
Table 2. Results.

\begin{tabular}{|c|c|c|c|c|c|c|c|c|}
\hline Case & $\begin{array}{c}\text { Age(years)/ } \\
\text { sex }\end{array}$ & Revision & Sides & $\begin{array}{l}\text { Frontal sinus } \\
\text { attachment }\end{array}$ & Procedure & 5-FU & Recurrence & $\begin{array}{l}\text { Follow-up } \\
\text { (months) }\end{array}$ \\
\hline 1. & $11 / F$ & Yes & Bilateral & Yes & Draf III/Draf III/ Draf III & No/No/Yes & Yes/Yes/No & $6 / 5 / 85$ \\
\hline 2. & $54 / \mathrm{M}$ & Yes & Left & Yes & Draf IIb & No & No & 74 \\
\hline 3. & $65 / M$ & No & Left & No & Draf IIb & No & No & 72 \\
\hline 4. & $64 / F$ & Yes & Right & No & Draf IIb & No & No & 72 \\
\hline 5. & $64 / M$ & No & Left & No & Draf IIb & No & No & 62 \\
\hline 6. & $43 / \mathrm{M}$ & Yes & Left & No & Draf IIb & No & No & 56 \\
\hline 7. & $82 / \mathrm{M}$ & No & Left & Yes & Draf IIb & No & No & 50 \\
\hline 8. & $37 / M$ & Yes & Bilateral & Yes & Draf III & Yes & No & 50 \\
\hline 9. & $47 / M$ & Yes & Right & Yes & Draf IIb & No & No & 46 \\
\hline 10. & $60 / M$ & Yes & Left & Yes & Draf IIb / Draf IIb & No/No & Yes/No & $93 / 41$ \\
\hline 11. & $83 / \mathrm{M}$ & Yes & Left & No & Draf IIb & No & No & 36 \\
\hline 12. & $49 / M$ & Yes & Bilateral & Yes & Draf III & No & No & 32 \\
\hline 13. & $43 / M$ & Yes & Right & Yes & Draf III & No & No & 30 \\
\hline 14. & $56 / M$ & Yes & Bilateral & Yes & Draf III (revision) & Yes & No & 20 \\
\hline 15. & $46 / \mathrm{M}$ & Yes & Right & No & Draf IIb & Yes & No & 19 \\
\hline 16. & $45 / F$ & No & Left & Yes & Draf III & Yes & No & 18 \\
\hline 17. & $63 / M$ & Yes & Right & Yes & Draf IIb & Yes & No & 18 \\
\hline 18. & $50 / \mathrm{M}$ & Yes & Bilateral & Yes & Draf III & No & No & 17 \\
\hline 19. & $52 / \mathrm{M}$ & No & Right & Yes & Draf IIb & Yes & No & 17 \\
\hline 20. & $59 / \mathrm{M}$ & Yes & Bilateral & Yes & Draf III & Yes & No & 16 \\
\hline
\end{tabular}

for possible adverse drug reactions. The minimum follow-up after the first procedure in our centre was 12 months.

\section{Results}

\section{Patients}

A total of twenty patient cases (5 primary and 15 revision cases) of IP involving the frontal sinus were retrieved over a ten -year period (January 2003 through March 2013). The male to female ratio was 5.7:1. The mean age at last intervention was 53.7 years (range 11 to 83 years). Table 2 lists the results.

\section{Attachment and diagnosis}

In fourteen patients, the IP was attached inside the frontal sinus. Eleven of these patients (79\%) were revision cases. Six patients had an attachment in the frontal recess with extension of tu- mour bulk into the frontal sinus. Our recurrent cases (2) involved frontal attachment of the IP.

Six patients (30\%) had IP involving both sides of the nose, all with frontal sinus attachment of the bilateral disease ( $43 \%$ of frontal origin IP). All six of these patients underwent a Draf III procedure. There was recurrence in one patient (case 1). In three of the primary cases, the origin of the IP was frontal, and attachment in two cases was in the frontal recess. None of the cases involved local dysplasia or malignant degeneration. None of the topographic biopsies, which were taken in five cases, indicated residual IP.

\section{Procedures}

A total of 23 procedures were performed on 20 patients. Ten of these were Draf III procedures, and the rest were Draf IIb. Fifteen 


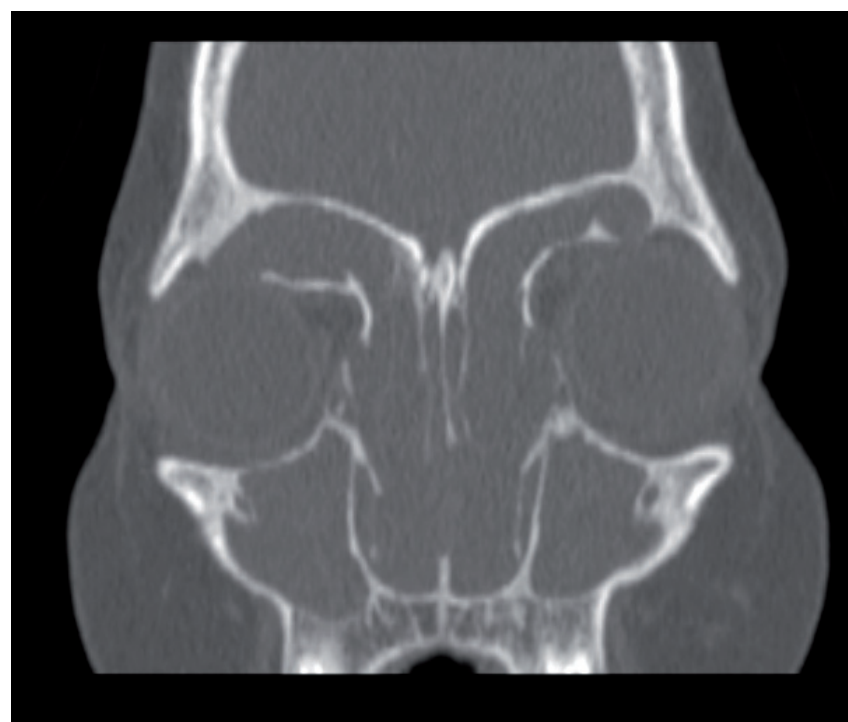

Figure 2. Coronal CT image showing orbital defects.

patients (75\%), were revision cases. One Draf III procedure (case 16) was performed in a primary case. A Draf III procedure was eventually performed in $42 \%$ of this population. An external approach was not required in any of our patients.

\section{Recurrence and follow-up}

The mean disease-free follow-up in the whole series after the last intervention was 42 months (SD 22.1).

We had five primary cases. The mean age at surgery was 62 (SD 12.7). There were not recurrences during a mean follow-up of 44 months (SD 22.6)

We had two recurrences in fifteen revision cases.

Case 10, a 60-year-old male, presented with recurrent IP attached inside the frontal sinus twenty years after a lateral rhinotomy procedure on the same side. A Draf Ilb was performed, resulting in a disease-free interval of 93 months before recurrence was detected. Another Draf Ilb was performed with drilling and coagulation of the attachment site and he has been disease-free for 41 months. Case 1, which required two revisions of a Draf III procedure, is described below.

Case of 11-year-old girl with bilateral frontal Schneiderian papilloma

Case 1 was an 11-year-old girl with massive polyposis leading to orbital defects who tested negative for cystic fibrosis (Figures $2 \& 3)$. Pathological examination of the polyps showed Schneiderian papilloma (exophytic and inverted). After an endoscopic Draf III procedure to remove all the polyps and diseased mucosa, followed by the drilling and coagulation of the attachment sites, it only took six months for the disease to recur (Figure 4). An endoscopic revision of the procedure brought relief for 5 months only, after which the whole nasal cavity was filled again

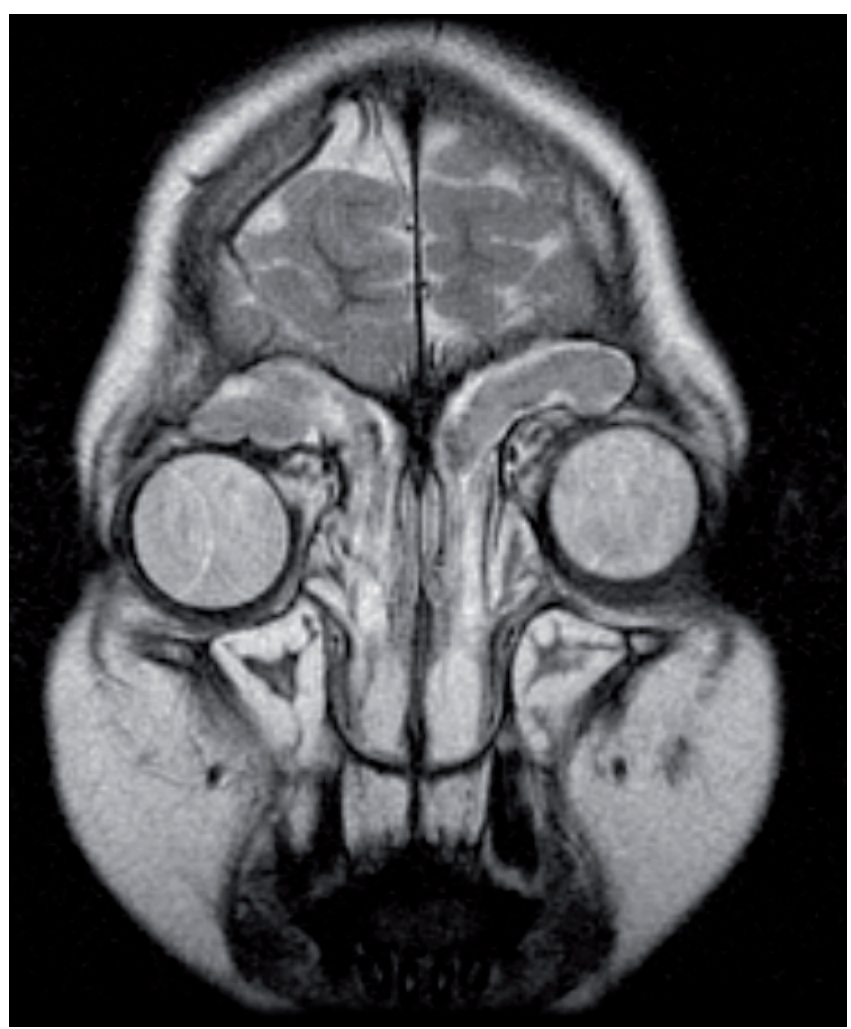

Figure 3. Coronal T2-weighted MRI image of inverted papilloma.

with disease. At the second endoscopic revision, the last author decided to apply a gauze coated in 5-FU cream at the end of the procedure in the surgical cavity and left it there for one week (comparable with the experience of the last author in adenocarcinoma). After a period of careful postoperative cleaning, the patient has remained disease-free until the time of this manuscript (85 months). Given this experience, we started using 5-FU in cases of IP involving either rapid recurrence in the past or when the surgeon was not entirely sure that all diseased mucosa with a margin had been totally removed, for example at bony defects, on the orbital roof or the cribriform plate.

\section{5-fluorouracil}

5-FU has been used in seven cases (cases 8, 14-17, 19 and 20) since. None of them have suffered recurrence as yet during an average follow-up of 23 months ranging from 16 to 50 months. Three of them were bilateral cases and all except cases 16 and 19 were revision cases.

In all cases the IP attachment was inside the frontal sinus, with the exception of case 15. In this revision case, the IP seemed to be broadly attached at the lamina papyracea, skull base and maxillary sinus posterior wall without a clear single attachment site. Of the remaining six cases, four underwent a Draf III procedure and two (cases 17 and 19) a Draf Ilb. In case 17 a lot of fibrotic scar tissue was encountered which was difficult to remove. Case 19 had an attachment site high on the posterior 


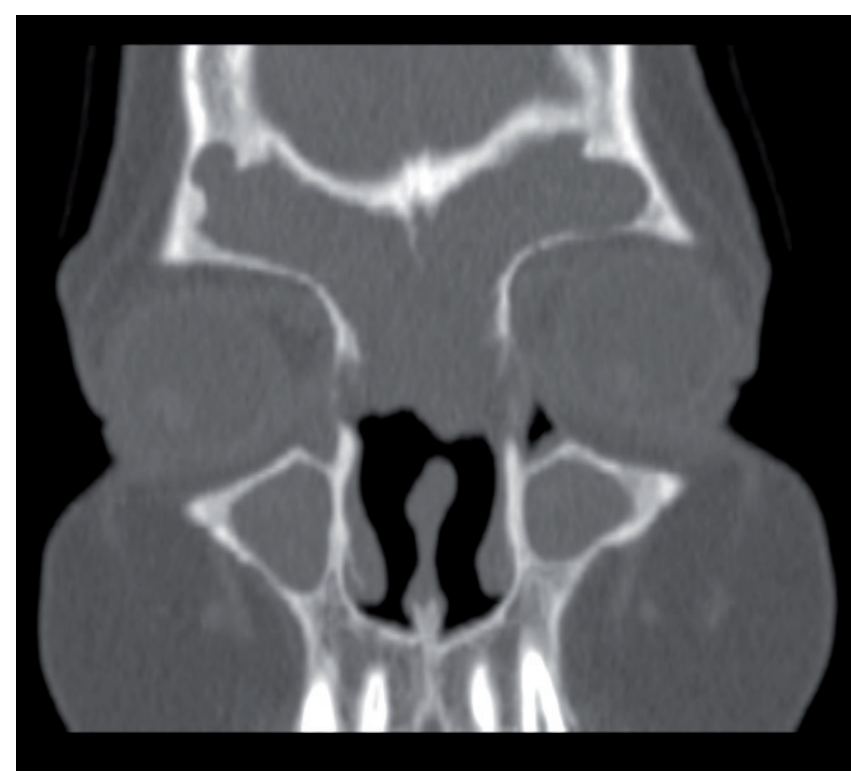

Figure 4. Coronal CT image 6 months after first Draf 3 procedure.

wall of the frontal sinus. Of the four Draf III procedures, three were bilateral cases and one was a left-sided case (case 16). In this primary, one-sided case the attachment of the IP was at the level of the orbital roof at a relatively lateral location in the frontal sinus, requiring a Draf III for access. It was difficult to be sure that all underlying periosteum had been removed. In the remaining three revision bilateral cases a Draf III was performed and 5-FU was used because of the extent of the pathology, the attachment on the cribriform plate and uncertainty about the complete removal of mucosa and mucoperiosteum laterally on the orbital roof.

One case (case 19) experienced a temporary periorbital swelling. The 5-FU pack was left in place, a course of prednisone was given, and the swelling subsided with no residual damage.

\section{Discussion}

Inverted papilloma involving the frontal sinus is rare. As a result, only small series are available, with small numbers of cases. In 2008, Zhang et al. published a retrospective case series of nine patients with IP involving the frontal sinus treated endoscopically with either Draf Ila or Draf Ilb. The average follow-up period was 15 months. They stress the importance of the intraoperative localisation of the tumour attachment with complete removal of the tumour pedicle and surrounding mucosa ${ }^{(19)}$. Kamel reported on six cases of frontal sinus IP, differentiating between attachment outside and inside the frontal sinus. He also successfully managed all cases endoscopically, performing Draf Ila, Ilb or III and removing the surrounding mucosa, and drilling or curetting underlying bone at the attachment sites. No recurrence was identified during an average follow-up of 27 months ${ }^{(20)}$. A systematic review of the period 1995-2010 analysed 49 cases from 11 studies, 31 of which were treated endoscopically. A high prevalence of revision (51\%) and bilateral (16.3\%) cases in frontal sinus IP was reported. The overall rate of recurrence was $22 \%$, including endoscopic endonasal (31 cases, 26\% recurrence), external ( 13 cases, $18 \%$ recurrence) and combined approaches (5 cases, 9\% recurrence). Mean follow-up time was 27 months ${ }^{(21)}$. Our series comprises twenty patients, all endoscopically treated in a single centre, with a high prevalence of recurrent (75\%) and bilateral (30\%) cases in the patients referred to us, confirming the findings of Walgama et al. ${ }^{(21)}$. However, we had only two recurrences (10\%) ourselves: cases 1 and 10. After revision procedures, there were no recurrences prior to the drafting of this paper during a mean follow-up of 42 months (SD 22.1).

A minimum follow-up of 12 months was adopted since most recurrences seem to occur within this period ${ }^{(6)}$. It is debatable whether IP recurring within 12 months is truly a recurrence; it may actually be residual disease after incomplete removal during prior surgery. In more than half of all the IP cases requiring revision surgery in the last ten years $(n=121)$ in our clinic, recurrent disease was detected more than one year after the first operation, with recurrences up to seven years after initial surgery. We therefore advocate lifelong follow-up, which is longer than the 3-year period stated in the European position paper ${ }^{(1)}$.

A critical point in this retrospective series is that our revision cases are probably a mixture of residual IP caused by incomplete resection and true recurrent IP after complete removal, both in other centres. This also applies to cases our own cases that we consider to be recurrences. We do not routinely take frozen sections of tumour margins during IP surgery. This may have affected our recurrence rate. As far as we are aware, it is not known whether there is a difference in the increased risk of subsequent recurrence after revision surgery for true recurrence or for residual disease.

A similar consideration applies to the initial attachment site. We looked only at the attachment of the IP during surgery in our centre. As a result, in the frontally attached group, we cannot be sure whether the true origin of the IP was inside the frontal sinus or whether these cases involved residual disease growing into the frontal sinus. Nevertheless, the complete removal of the attachment site(s) is the most important factor in recurrence ${ }^{(4)}$. Since removal is more difficult when the IP is attached inside the frontal sinus, we believe this is an important clinical division in IP involving the frontal sinus.

The strength of this study, in addition to the relatively large number of cases, is the description of the study population with respect to the attachment of the IP and the procedures performed. This allows for several observations. In this series, for example, all bilateral IPs involved frontal sinus attachment, 
and they were revision cases in which a Draf III was performed. Furthermore, our recurrences were cases in which the IP was attached inside the frontal sinus. In addition to the surgical strategy of complete tumour removal with a margin of mucosa, and the drilling or coagulation of the attachment site as described in the European position paper by Lund et al. ${ }^{(1)}$, we started using topical 5-FU in selected cases.

The recurrence rate in this series was low and incorporating local treatment with 5-FU in the immediate postoperative period in selected cases may have contributed to these results. After the initial success in case 1, with a disease-free follow-up of seven years at present, we used 5-FU in seven cases. All but one had a frontal sinus attachment of the IP, and none have recurred yet. The efficacy of 5-FU seems excellent: we have not had any recurrences in this series after using $5-\mathrm{FU}(\mathrm{n}=8)$ and one recurrence in all our other IPs not involving the frontal sinus where we used 5-FU $(n=10)$. However, the possibility of side-effects should be considered when using this treatment. Literature on the topical use of 5-FU in the sinuses is very limited and most papers address the treatment of sinonasal adenocarcinoma. In a series of 62 cases of adenocarcinoma treated with surgical debulking and repeated applications of 5-FU and necrotectomy during the first four weeks of the postoperative period, temporary periorbital swelling is mentioned, but primarily in the cases where the tumour involved the lamina papyracea ${ }^{(24)}$. We have seen this ourselves on one occasion, with a self-limiting course and no residual damage. There is more experience with topical 5-FU in ophthalmology as an adjunctive treatment to the excision of surface squamous neoplasia, where it is described as a safe and effective treatment. Side-effects are transient and include lid toxicity, superficial keratitis and epithelial defect ${ }^{(26)}$. Topical use in the treatment of HPV-induced anal intraepithelial neoplasia has also been reported to be safe, with any side-effects comprising local irritation and inflammatory reactions only ${ }^{(27)}$. To treat verruca vulgaris in children, 5-FU was applied to 39 children once or twice daily for 6 weeks, with assessments being made of, among other factors, side-effects at 6 weeks, 3 and 6 months, and blood tests and medication blood levels at 6 weeks.

Transient side-effects included erythema, erosion and hyperpig- mentation. Blood levels were below quantification limits for 38 of 39 subjects $(<0.1 \mathrm{ng} / \mathrm{mL}$ ) (28). The leading application pf 5-FU is in preneoplastic skin conditions like sun-induced keratosis or superficial basalioma. The FDA prescribing information lists local irritation reactions like burning, crusting, erosions, pain and inflammatory reactions like dermatitis and ulceration. It also states leukocytosis as the most frequent haematological side-effect. The amount applied locally will result in no, or only very limited, systemic uptake. Systemic absorption studies in which patients with actinic keratosis, after 2-3 weeks of topical treatment, applied 1 gram of labelled 5-FU to the entire face for 12 hours showed, by analysing urine samples, that approximately $5.98 \%$ of the topical dose was absorbed systemically. Another study showed that, after three days of labelled treatment, no amounts were found in plasma, urine or expired $\mathrm{CO}_{2}$. In our limited experience we have found that 5-FU is well tolerated topically and we propose to use it as an adjunct therapy after endoscopic sinus surgery for IP when the surgeon cannot be completely sure about the complete removal of the IP or when the IP recurs rapidly. The surgical removal of all attachment sites remains the primary therapeutic goal and it cannot be replaced by applying 5-FU. We applied 5-FU generously on a jelonet dressing and left it in place for a week before thorough cleaning at the outpatient clinic, and we experienced only one case of selflimiting periorbital swelling with no residual damage.

Of course, no treatment effect can be inferred from a case series. However, we do find our results promising. Ideally a prospective trial should be performed but the scarcity of frontal IP will be a problem. Establishing the safety or side-effects of the topical use of 5-FU in the postoperative treatment of endoscopic sinus surgery for IP seems more feasible and an interesting next step.

\section{Authorship contribution}

GFJPMA: data collection, statistical analysis, writing / editing manuscript; MW van der Hout: data collection, writing manuscript; SMR, CG, WJF: data production, editing manuscript.

\section{Conflicts of Interest}

No conflicts of interest exists

\section{References}

1. Lund VJ, Stammberger $H$, Nicolai $P$, Castelnuovo P, Beal T, Beham A, et al. European position paper on endoscopic management of tumours of the nose, paranasal sinuses and skull base. Rhinology Supplement 2010(22): 1-143.

2. Hasegawa M, Deng Z, Maeda H, Yamashita Y, Matayoshi S, Kiyuna A, et al. Human papillomavirus load and physical status in sinonasal inverted papilloma and squamous cell carcinoma. Rhinology 2012;50(1): 87-94.
3. Lawson W, Ho BT, Shaari CM, Biller HF. Inverted papilloma: a report of 112 cases. Laryngoscope 1995;105(3 Pt 1): 282-8.

4. Lawson W, Kaufman MR, Biller HF. Treatment outcomes in the management of inverted papilloma: an analysis of 160 cases. Laryngoscope 2003;113(9): 1548-56.

5. Yoon JH, Kim CH, Choi EC. Treatment outcomes of primary and recurrent inverted papilloma: an analysis of 96 cases. J Laryngol Otol. 2002;116(9): 699-702.

6. Von Buchwald C, Larsen AS. Endoscopic surgery of inverted papillomas under image guidance--a prospective study of 42 consecutive cases at a Danish university clinic. Otolaryngol Head Neck Surg. 2005 Apr;132(4): 602-7.

7. Christensen WN, Smith RR. Schneiderian papillomas: a clinicopathologic study of 67 cases. Hum Pathol. 1986;17(4):393-400.

8. Lee TJ, Huang SF, Lee LA, Huang CC. Endoscopic surgery for recurrent inverted papilloma. Laryngoscope 2004;114(1): 10612. 
9. Tomazic PV, Hubmann F, Stammberger $H$. [The Problem of High Recurrence Rate in Endoscopic Revision Surgery for Inverted Papilloma.]. Laryngorhinootologie. 2015;94(7):447-50.

10. Lawson W, Patel ZM. The evolution of management for inverted papilloma: an analysis of 200 cases. Otolaryngol Head Neck Surg. 2009 Mar;140(3):330-5.

11. Bhalla RK, Wright ED. Predicting the site of attachment of sinonasal inverted papilloma. Rhinology 2009;47(4):345-8.

12. Lee DK, Chung SK, Dhong HJ, Kim HY, Kim $\mathrm{HJ}$, Bok KH. Focal hyperostosis on CT of sinonasal inverted papilloma as a predictor of tumor origin. AJNR Am J Neuroradiol. 2007;28(4):618-21.

13. Al Badaai Y, Chankowsky J, Mah M, Yammine N, Samaha M. Radiological localization of Schneiderian papilloma. Int Forum Allergy Rhinol. 2011;1(6):488-91.

14. limura J, Otori N, Ojiri H, Moriyama H. Preoperative magnetic resonance imaging for localization of the origin of maxillary sinus inverted papillomas. Auris Nasus Larynx. 2009 ;36(4):416-21.

15. Oikawa K, Furuta Y, Oridate N, Nagahashi T, Homma A, Ryu T, et al. Preoperative staging of sinonasal inverted papilloma by magnetic resonance imaging. Laryngoscope 2003;113(11):1983-7.

16. Savy L, Lloyd G, Lund VJ, Howard D. Optimum imaging for inverted papilloma. J Laryngol Otol. 2000;114(11):891-3.

17. Yousem DM, Fellows DW, Kennedy DW Bolger WE, Kashima H, Zinreich SJ. Inverted papilloma: evaluation with MR imaging.
Radiology 1992;185(2):501-5.

18. Busquets JM, Hwang PH. Endoscopic resection of sinonasal inverted papilloma: a meta-analysis. Otolaryngol Head Neck Surg. 2006;134(3):476-82

19. Zhang L, Han D, Wang C, Ge W, Zhou B. Endoscopic management of the inverted papilloma with attachment to the frontal sinus drainage pathway. Acta Otolaryngol. 2008;128(5):561-8.

20. Kamel RH, Abdel Fattah AF, Awad AG. Origin oriented management of inverted papilloma of the frontal sinus. Rhinology 2012;50(3):262-8

21. Walgama E, Ahn C, Batra PS. Surgical management of frontal sinus inverted papilloma: a systematic review. Laryngoscope 2012;122(6):1205-9.

22. Moore AY. Clinical applications for topical 5-fluorouracil in the treatment of dermatological disorders. J Dermatolog Treat. 2009;20(6):328-35.

23. Nanji AA, Sayyad FE, Karp CL. Topical chemotherapy for ocular surface squamous neoplasia. Curr Opin Ophthalmol.:24(4):336-42

24. Knegt PP, Ah-See KW, vd Velden LA, Kerrebijn J. Adenocarcinoma of the ethmoidal sinus complex: surgical debulking and topical fluorouracil may be the optimal treatment. Arch Otolaryngol Head Neck Surg. 2001;127(2):141-6

25. Almeyda R, Capper J. Is surgical debridement and topical 5 fluorouracil the optimum treatment for woodworkers' adenocarcinoma of the ethmoid sinuses? A casecontrolled study of a 20-year experience. Clin Otolaryngol. 2008;33(5):435-41.
26. Bahrami B, Greenwell T, Muecke JS. Longterm outcomes after adjunctive topical 5-flurouracil or mitomycin $\mathrm{C}$ for the treatment of surgically excised localised ocular surface squamous neoplasia. Clin Experiment Ophthalmol. 2014;42(4):317-22. 27.

27. Richel $\mathrm{O}$, Wieland $\mathrm{U}$, de Vries $\mathrm{HJ}$, et al. Topical 5-fluorouracil treatment of anal intraepithelial neoplasia in human immunodeficiency virus-positive men. $\mathrm{Br} J$ Dermatol.;163(6):1301-7.

28. Gladsjo JA, Alio Saenz AB, Bergman J, Kricorian G, Cunningham BB. 5\% 5-Fluorouracil cream for treatment of verruca vulgaris in children. Pediatr Dermatol. 2009;26(3):279-85

\section{G.F.J.P.M. Adriaensen}

Department of Otorhinolaryngology Academic Medical Centre (AMC)

\section{Amsterdam}

the Netherlands

Tel: +31-20-566 3789

Fax: +31-20-566 9662

E-mail: g.f.adriaensen@amc.uva.nl

\section{ANNOUNCEMENT}

\section{FELLOWSHIPS are $€ \mathbf{7 0 0 , -}$ each}

as a support to attend the Stockholm ERS-ISIAN

congress in Stockholm, July 3-6, 2016

\section{Requirements}

are offered by

FOUNDATION RHINOLOGY (20 fellowships) and EUROPEAN RHINOLOGIC SOCIETY (20 fellowships)
1. The candidate should be younger than 36 years of age,

2. Is member of the ERS

3. Will present a paper/poster at the Stockholm ERS-ISIAN congress

4. Has a letter of recommendation by a senior rhinologist or the head of the department

Go to the website to submit the application:

https://kenesit.wufoo.eu/forms/ers-2016-junior-member-grant- 